
рованного достижения заданного значения параметра оптического skew, может быть выполнено различными способами.

Время отклика центра обработки данных (ЦОД) на поступающий пользовательский запрос, которое является одним из главных критериев качества его функционирования, требует применения каналов связи с быстродействием 40 Гбит/с и выше. С учетом возможности современной микроэлектроники достигнуть такого значения в массовой аппаратуре можно только на основе параллельной передачи. В широкую инженерную практику внедрены две разновидности такой передачи, основанные на пространственном и спектральном мультиплексировании.

С учетом небольших длин трактов внутри цОД схема пространственного мультиплексирования со скоростью порядка 400 Гбит/с оказывается экономически более привлекательной, хотя уже на скорости 100 Гбит/с часто комбинируется со спектральным мультиплексированием (WDM).

Реализация удовлетворительных экономических параметров оборудования с пространственным мультиплексированием возможна только при выполнении норм по параметру "оптический перекос задержек" - skew (79 нс/100 м). Наиболее простой способ решения этой задачи - принудительное выравнивание физических длин отдельных оптических волокон (ОВ) с формированием сборок. Это может быть выполнено разными способами.

\section{ЛЕНТОЧНЫЕ СВеТОВОДЫ}

Минимальный оптический skew сравнительно просто достигается в классических ленточных световодах. Обращение к этой разновидности волоконной сборки в качестве основы конструкции сердечника транковых кабелей целесообразно также тем, что не требует выполнения новых разработок: компоненты просто заимствуются из кабелей общего назначения.

При формировании ленточного световода отдельные волокона параллельно укладываются рядом друг с другом с определенным шагом, после чего тем или иным способом скрепляются. Функции средства механической фиксации отдельных ОВ в структуре ленты берет на себя вторичное защитное покрытие. Вторичное защитное покрытие ленточных структур может быть реализовано по-разному.

Первый внедренный в широкую инженерную практику способ был разработан Лабораториями Белла корпорации AT\&T. В его основу положена наклейка отдельных ОВ на пленку из полиэфирной смолы (акрилата). Для достижения более высокой механической стабильности использовалась двух сторонняя наклейка, то есть волокна находились между двумя лентами (рис.1a).

Главным недостатком данного метода стала невысокая механическая прочность подобной структуры, в первую очередь слабая сопротивляемость боковым 


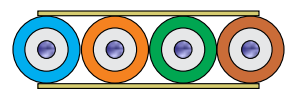

a)

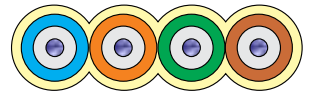

6)

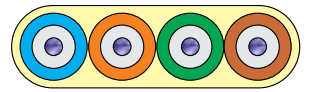

B)

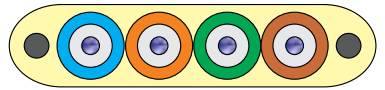

r)

Рис.1. Варианты формирования ленточных волокон: а - на основе наклейки на пленку; б - с заполнением междуволоконного пространства полиэфирной смолой; в - заключение в общую оболочку; г-с силовыми элементами для увеличения разрывной прочности

сдвигающим воздействиям. Способом устранения этого недостатка стал переход на схему заполнения акрилатом промежутка между отдельными световодами (рис.1б).

Еще одним вариантом исполнения ленты стало размещение группы параллельно уложенных волокон в общей оболочке с гладкой поверхностью (рис.1в). Такая конструкция усиливает защиту от внешних механических воздействий и почти не увеличивает внешние габариты изделия.

Количество световодов в отдельной ленте зависит от назначения оптического кабеля (OK), выбранной схемы организации связи с учетом перспектив развития и может составлять 2, 4, 6, 8 и 12. В магистральных изделиях внешней прокладки часто применяются 24-волоконные ленты. Для внутриобъектовых транковых ОК систем параллельной передачи с учетом принятой в аппаратуре схемы организации информационного обмена используются ленты с 8, 12 и 16 волокнами. При необходимости увеличения количества световодов в состав сердечника транкового кабеля вводится несколько одинаковых лент.

Стойкость ленты к растягивающим усилиям наращивается увеличением ее ширины и дополнением 


\section{Таблица 1. Некоторые параметры типовых кон- струкций ОК внешней прокладки большой емко- сти компании Corning}

\begin{tabular}{|l|c|c|}
\hline \multirow{2}{*}{$\begin{array}{l}\text { Параметр } \\
\text { Количество волокон }\end{array}$} & \multicolumn{2}{|c|}{ Разновидность конструкции } \\
\cline { 2 - 3 } & Модульная & Ленточная \\
\hline Внешний диаметр, мм & 21,3 & 432 \\
\hline $\begin{array}{l}\text { Плотность конструк- } \\
\text { ции, мм²/волокно }\end{array}$ & 1,26 & 14,2 \\
\hline $\begin{array}{l}\text { Погонная масса, кг/км } \\
\text { Допустимое растяги- } \\
\text { вающее усилие, Н }\end{array}$ & 370 & 328 \\
\hline
\end{tabular}

двумя силовыми элементами, расположенными в ее краевых областях (рис.1г).

Главным преимуществом формирования сердечника на основе ленточных ОВ становится возможность достижения очень высокой общей плотности конструкции. В большей степени она проявляется в ОK с большим количеством волокон. Если сравнить между собой изделия с близкими характеристиками, то в части плотности конструкции ленточное исполнение превосходит традиционную многомодульную конструкцию примерно в 3,4 раза, по меньшей мере не уступая по остальным характеристикам (табл.1).

Основными недостатками ленточных кабелей считаются:

- отличие формы поперечного сечения от круглой (при небольшом количестве волокон);

- сложность сварки и полевой установки разъемов.

Последний недостаток легко устраняется массовым применением модульно-кассетных и претерминированных решений.

\section{КВАЗИМОДУЛЬНАЯ КОНСТРУКЦИЯ}

Квазимодульная конструкция разработана и серийно выпускается под брендом j-FiberUnit немецкой компанией j-fiber. Структура такого рода не имеет своего отдельного наименования и называется квазимодульной из-за своего конструктивного и внешнего сходства с классическими модулями обычного ОК. Своему ленточному функциональному аналогу она несколько уступает по параметру плотности конструкции, при этом из-за отсутствия механической связи

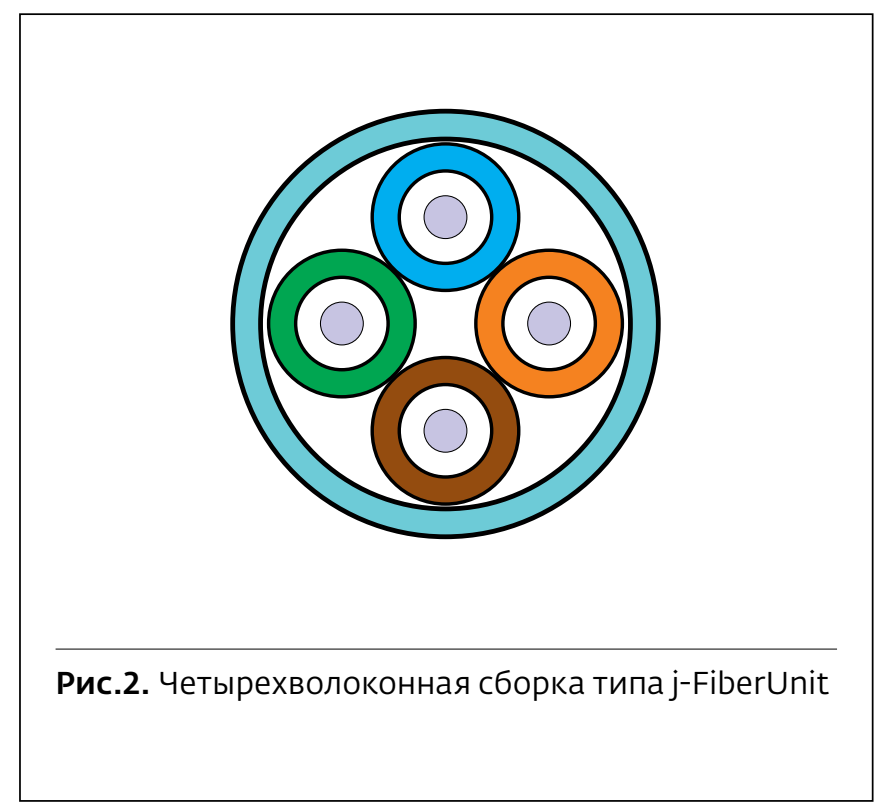

отдельных волокон друг с другом заметно превосходит его в части гибкости и простоты разделки. Немалое значение имеет удобная круглая форма поперечного сечения.

Конструктивно квазимодульный элемент представляет собой несколько ОВ в первичном защитном покрытии (в серийных изделиях их количество составляет 2, 4, 6, 8 или 12), которые образуют регулярную структуру и без зазоров уложены внутри тонкостенной трубчатой оболочки. Принудительное выравнивание оптических длин отдельных световодов происходит за счет:

- применения однотипных ОВ;

- регулярного характера расположения световодов;

- плотного охвата ОВ внешней оболочкой.

Совокупность этих решений обеспечивает паспортное значение skew не более 0,1 нс при длине в 100 м, то есть достигается более чем 7,5-кратный запас по сравнению с требованиями IEEE. При специальном заказе разработчик гарантирует достижение skew на уровне 0,075 нс/100 M, то есть увеличивает запас относительно норм до десятикратного.

Для улучшения условий установки элементов оптических разъемов использована стан ${ }^{-}$ дартная по IEC 60304 цветовая окраска первичного защитного покрытия ОВ. Предусмотрена защита от влаги заполнением пустот легко удаляемым гидрофобным гелем. Поперечное сечение 4-волоконной сборки j-FiberUnit изображено на рис.2. 12-волоконный вариант имеет четырехслойную регулярную структуру укладки ОВ по схеме $2+4+4+2$. 


\section{TEXНологИя SPIDERWEB}

Данная технология разработана компанией Fujikura с целью улучшения массогабаритных характеристик многоволоконных ОК. Лента световодов SpiderWeb включает в себя 12 волокон в первичном защитном покрытии. Соседние волокна механически связаны друг с другом на коротком участке оболочки. Для увеличения результирующей плотности конструкции лента сворачивается в трубку по схеме 3-4-3-2 (рис.3) и помещается внутрь защитной оболочки с относительно небольшим диаметром.

При растяжении лента приобретает вид сетки. При необходимости волокна легко отделяются друг от друга обычным тянущим движением "на разрыв", под воздействием которого разрушается фиксирующая перемычка. Структура ленты, использованная разработчиком, в сочетании с отсутствием вторичного защитного покрытия обеспечивает изделию не только очень низкую жесткость, но и возможность изгиба с достаточно малым радиусом. Последнему дополнительно способствует возможность перемещения волокон в поперечном направлении в местах поворотов изделия.

Отсутствие вторичного защитного покрытия обеспечивает значимое улучшение
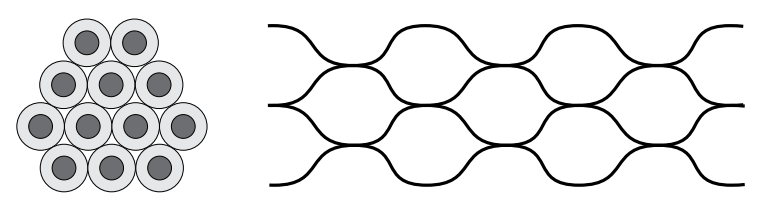

Рис.3. Некоторые особенности ленточного волокна SpiderWeb: a - структура 12-волоконной ленты в свернутом состоянии; 6- фрагмент ленты в расправленном и растянутом состоянии

массогабаритных показателей кабеля. Например, 1728-волоконный кабель внешней прокладки с обычным для таких изделий допустимым растягивающим усилием $2700 \mathrm{H}$ имеет диаметр всего 21,8 мм (37\% преимущество по сравнению с аналогами) при погонной массе 340 кг/км (выигрыш в 2,8 раза относительно многотрубочных ленточных конструкций). Большая ширина ленты 


\section{0}

a)

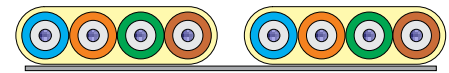

6)

\section{0}

B)

Рис.4. Варианты исполнения ленточных световодов для облегчения выполнения отводов: а - в общей оболочке; 6 - с разрывами между отдельными группами; в - с фигурной внешней поверхностью ленты

позволяет использовать эффективную кодировку окраской первичного защитного покрытия.

С точки зрения параллельной передачи важное значение приобретает наличие механической связи отдельных ОВ друг с другом. За счет этого заметно облегчается достижение минимального значения оптического skew. Поэтому ленты SWR вполне могут быть использованы при организации разрешенных стандартом 500-метровых одномодовых соединительных линий.

Наибольшие преимущества технология SpiderWeb обеспечивает при создании ОК внешней прокладки с большим количеством волокон. Кроме того, структура ленты полностью согласована с технологическими инструментами групповых сварочных аппаратов.

Для линий аппаратного зала ЦОД и аналогичных объектов с небольшой волоконностью и отсутствием сварочных работ особых преимуществ изделие не дает. Исключением является круглая форма поперечного сечения. Многомодовые транковые кабели с внешним диаметром 3 мм на основе ленты SpiderWeb и усилением оплеткой из кевларовых нитей в 12- и 24-волоконном вариантах предлагаются американской компании AFL.

\section{ОБЕСПЕЧЕНИЯ ОТВОДОВ ОТ ЛЕНТЫ СВЕТОВОДОВ}

В технике параллельной передачи популярны разнообразные шнуры и линейные кабели с конфигурацией вида "n в m", в которых хотя бы один из параметров (n или m) отличается от единицы.

Кабельные изделия для параллельной передачи реализуются преимущественно на основе ленточных световодов. Из-за высокой плотности прилегания отдельных волокон друг к другу и интегрального характера ленты отделение от нее отдельных групп световодов, что требуется для выполнения отводов, становится непростой задачей. В процессе ее решения предложено несколько подходов, заметно упрощаю щих осуществление этой процедуры.

Первый вариант основан на помещении отдельных механически несвязанных между собой лент внутрь общей оболочки. Фактически в форме так называемого разделяемого (англ. split) ленточного световода (рис.4а) реализуется ленточный микрокабель.

Группы ОВ достаточно просто отделяются друг от друга в том случае, если изначально находятся в составе общей ленты, но при этом располагаются с определенным зазором (например, по образцу, показанному на рис.4б). Прямое применение такой ленты нецелесообразно из-за ее габаритов и повышенной "ломкости" в поперечном направлении. Для устранения этих недостатков можно перейти на ленту с двумя боковыми отводами-крыльями и соответ ствующими впадинами на внешней поверхности. Отводы и впадины могут формироваться за счет увеличенной толщины общей скрепляющей оболочки по образцу рис.4в. Образующаяся в результате структура используется для крепления отдельных групп ОВ друг к другу, увеличивая ее поперечную жесткость. Одновременно такое исполнение ленточного волокна позволяет легко отделить группы световодов в случае возникновения необходимости.

\section{Выводы}

Серийно производимые волоконные сборки для транковых кабелей обеспечивают 7-10-кратный запас по параметру skew, который может быть направлен на увеличение дальности связи.

Развитие техники специализированных ОВ для транковых кабелей параллельной передачи идет в направлении создания структур, позволяющих получить наиболее эффективную для эксплуатации круглую форму поперечного сечения.

Задача отделения отдельных световодов от группы, что необходимо для создания отводов, сегодня может считаться решенной в полном объеме. 